\title{
Dos casos de ciclones tropicales atlánticos: Ike (Sep 2008) y Álex (Jul 2010)
}

RAMÓN VÁZQUEZ PÉREZ-BATALLÓN

Centro Nacional de Predicción (CNP), Agencia Estatal de Meteorología (AEMET)

\author{
Vai alta a nuvem que passa \\ Vai alto o meu pensamento \\ Que é escravo da tua graça \\ Como a nuvem o é do vento.
}

Quadras ao Gosto Popular - FERNANDo PESSOA

En el campo de la meteorología tropical uno de los retos operativos más importantes es el pronóstico de trayectorias de los ciclones tropicales. Este capítulo esta basado en material utilizado en el curso o taller sobre aplicaciones de los productos del European Centre for Medium-range Weather Forecasts (ECMWF, cap. 19 en la página 289) a la meteorología tropical, celebrado en La Antigua, Guatemala, en los años 2011 y 2013, en el que participaron la AEMET, el ECMWF y la Agencia Española de Cooperación Internacional para el Desarrollo (AECID). En él se comentan distintos aspectos relacionados con la predicción operativa de dos situaciones de ciclones tropicales atlánticos y se compara el comportamiento de los sistemas predictivos del ECMWF, el modelo determinista ECHRES (sec. 19.2 en la página 291) y del sistema de predicción por conjuntos (SPC) ECENS (sec. 19.3 en la página 293) en ambos casos, tratando de hacer énfasis en el valor añadido a las predicciones deterministas del ECHRES por parte de distintos productos basados en el ECENS.

Palabras clave: sistemas de predicción por conjuntos aplicados a la predicción de corto y medio plazo, predicción probabilista, ciclones tropicales, huracán Ike, huracán Álex. 

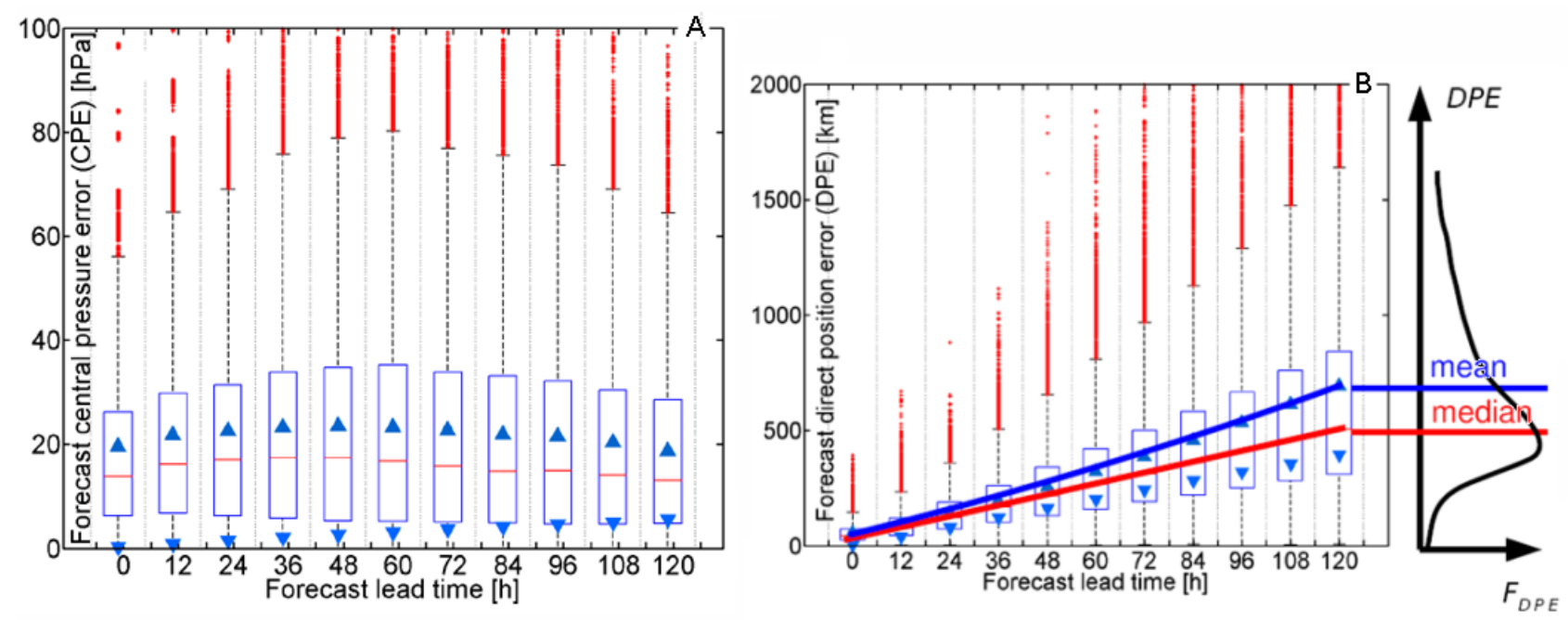

Figura 46.1: Evolución en el tiempo de los errores de intensidad (A) y posición (B) del trazador de ciclones tropicales del ECENS [1].

\subsection{Introducción}

En el campo de la meteorología tropical uno de los retos operativos más importantes es el pronóstico de trayectorias de los ciclones tropicales [6]. Dado el elevado grado de incertidumbre de este tipo de pronósticos, el valor añadido a las predicciones deterministas por los sistemas de predicción por conjuntos es apreciable, pues nos permiten valorar dicha incertidumbre de manera objetiva y recogiendo la dinámica de la atmósfera y sus posibles alternativas en cada situación. Si además se añaden perturbaciones locales en el entorno del ciclón para generar las trayectorias de los distintos miembros del sistema de predicción por conjuntos (SPC), en este caso el ECENS (sec. 19.3 en la página 293), se obtiene una mejora añadida en los pronósticos [4]. No obstante, existen métodos que evalúan las incertidumbres a partir de datos estadísticos, normalmente asociados a situaciones meteorológicas pasadas y análogas a la presente Es el caso del conocido cono de probabilidad del National Hurricane Center (National Hurricane Center (NHC) [8]).

Habitualmente se utilizan dos medidas de incertidumbre en el pronóstico de ciclones tropicales: el error de posición (distancia entre trayectoria prevista y observada) y el error en intensidad (diferencia en el valor de la presión central del ciclón previsto respecto al observado), Figura 46.1.
En general, el error de posición en la trayectoria de un ciclón tropical crece de forma clara con el tiempo, pero no así, curiosamente, el error en intensidad. De acuerdo con los estudios de Yamaguchi [10], en lo que se refiere al pronóstico de trayectorias, la media del ECENS tiene mejor comportamiento que el miembro de control, y la mejora es mayor para rangos largos de predicción. Pero, por otra parte, también hay que tener en cuenta que la media no tiene por qué verificar mejor que la mitad de los miembros del SPC, y esto a veces puede ser un hándicap en el proceso de predicción. Según el estudio de Aemisegger [1], para el trazador de ciclones tropicales del ECENS, la distribución del error de posición está sesgada positivamente, es decir, para rangos de predicción largos, más del 50\% de los miembros del ECENS verifican mejor que la media (Figura 46.1 B). En cuanto a los errores en el valor de la presión central o intensidad, en este mismo estudio se concluye que dicho error se mantiene relativamente constante (Figura 46.1 A), aunque aumente el rango de predicción (el ECENS es sobreconfiado para este parámetro). En la fecha en la que se lea este capítulo es probable que los resultados aquí mostrados sean algo diferentes, dependiendo de la versión operativa del trazador de ciclones tropicales. En cualquier caso, un predictor operativo debería tener en cuenta en sus pronósticos el comportamiento estadístico de los errores de posición e intensidad del trazador en uso en su servicio meteorológico, pues tal conocimiento añadirá valor a sus predicciones. 

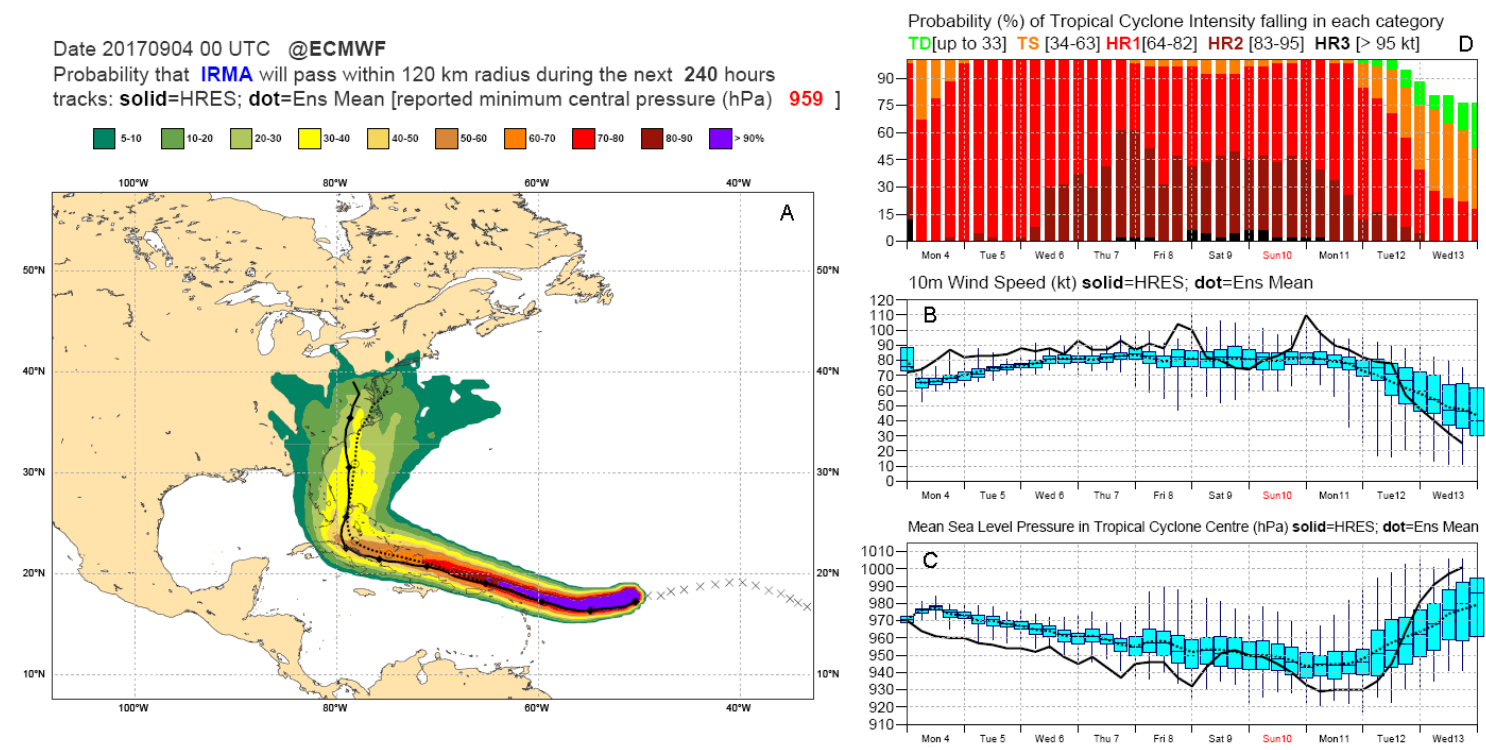

Figura 46.2: Probabilidades de impacto (A), EPSgramas lagrangianos (B y $C$ ) y probabilidades de caer en cada categoría (D) para el ciclón tropical Irma. ECENS y ECHRES (en trazo negro), 04-09-2017 00 UTC. ECMWF 2017.

El producto operativo del ECMWF que se viene utilizando para representar las incertidumbres en la trayectoria de un ciclón, es el mapa de probabilidades de impacto (strike probability, ver 27.7.4 en la página 422 [4]), que da la distribución espacial de la probabilidad de que un ciclón tropical «caiga» en un círculo de radio $120 \mathrm{~km}$ durante las próximas 240 horas (Figura 46.2 A). Para representar las incertidumbres en intensidad se utilizan los EPSgramas lagrangianos, que dan la evolución temporal de la distribución de la presión central y velocidad máxima asociadas al ciclón y la probabilidad de caer en cada categoría. Se muestra un ejemplo en las Figuras 46.2 B y 46.2 D.
La señal del modelo determinista para estos dos parámetros de intensidad puede parecer, en principio, mejor o más realista, pero esto es engañoso. A menudo, cuando el modelo determinista todavía no ha generado el ciclón ya hay miembros del ECENS que sí lo han hecho, o viceversa, no es raro el caso en que el modelo determinista lo disipa, mientras hay miembros del ECENS que mantienen el ciclón en el tiempo. No obstante, dada su menor resolución espacial, los miembros del ECENS tienden a subestimar los máximos de intensidad de un ciclón tropical en la mayoría de casos.
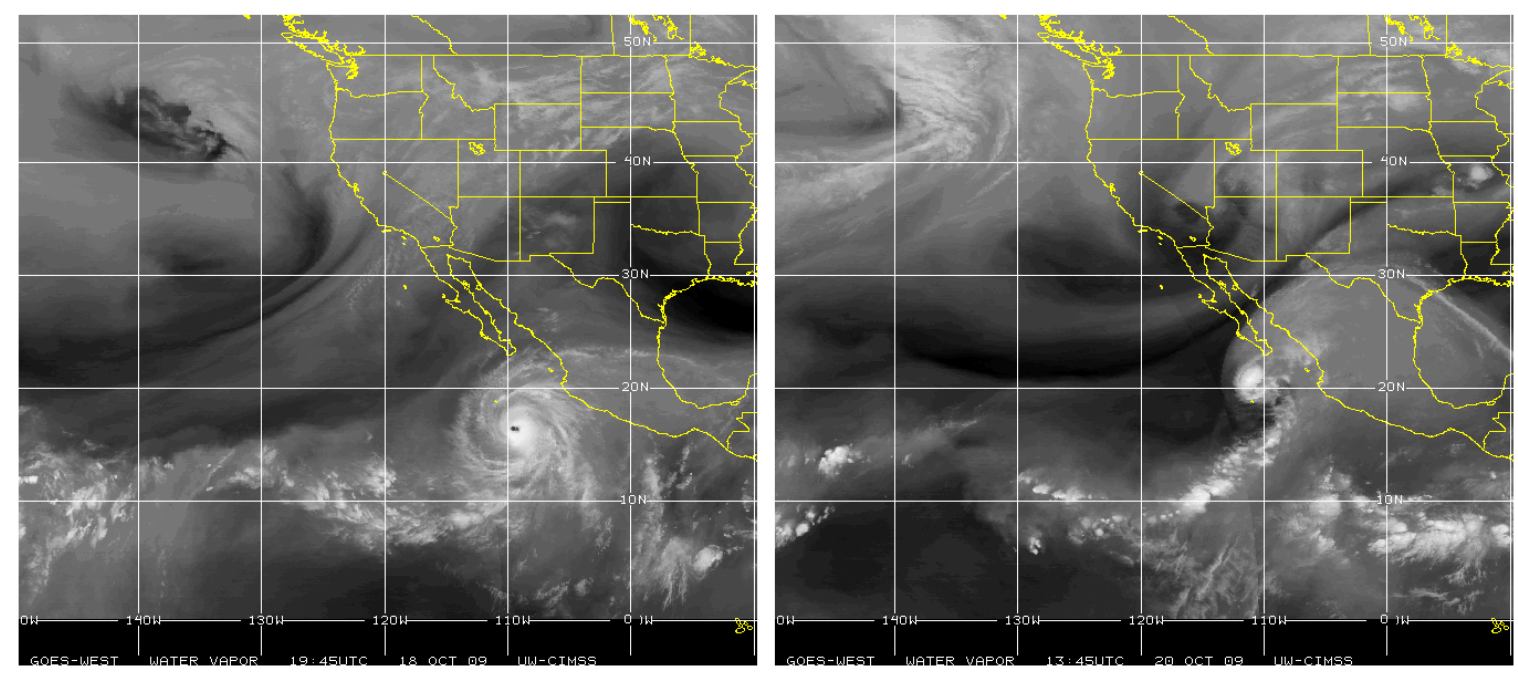

Figura 46.3: Imágenes del canal vapor de agua del 18 de octubre de 2009 a las 19:45 UTC y del 20 de octubre a las 13:45. Ciclón tropical Rick. Fuente: CIMSS. 
Una vez iniciada la génesis de un ciclón tropical, una de las mayores fuentes de incertidumbre en cuanto a la trayectoria del mismo proviene de la interacción con sistemas de latitudes extratropicales y de las incertidumbres asociadas a los ciclos de vida de tales sistemas, como por ejemplo las asociadas a las ciclogénesis de latitudes medias en el entorno del ciclón o al comportamiento de las dorsales subtropicales, que muchas veces hacen el papel de «guía» de las trayectorias. Las imágenes de vapor de agua son de gran utilidad en el diagnóstico y en el «diagnóstico a posteriori» de las posibles fuentes de error $\mathrm{y}$ «bandazos» entre pasadas y en el pronóstico de corto plazo. En la Figura 46.3 en la página anterior se muestran dos imágenes, correspondientes al ciclón tropical Rick, que pueden servir de ejemplo a este respecto. En este caso la incertidumbre sobre el lugar de impacto del ciclón en la costa de México está ligada a la incertidumbre en la evolución de la ciclogénesis de latitudes medias, más al norte.

En este capítulo vamos a ver dos ejemplos sobre la utilidad operativa de los productos basados en el ECENS, y el valor que añaden a las predicciones deterministas del ECHRES, en el pronóstico de trayectorias de ciclones tropicales $[4,5]$.

\subsection{Caso 1: Huracán Ike}

Ike fue un ciclón tropical histórico que tuvo lugar entre el 1 y 14 de septiembre de 2008. Durante buena parte de su ciclo de vida sostuvo la intensidad de huracán, alcanzando en bastantes periodos las categorías 3 y 4 dentro de la escala Saffir-Simpson, como vemos en la Figura 46.4, tomada del NHC Tropical Cyclone Report correspondiente para este huracán [3]. Una parte interesante de esta situación meteorológica fue el comportamiento de los modelos en el medio plazo.

Ike llegó a la isla de Cuba el día 8 de septiembre como un huracán de categoría 4. Vamos a revisitar el pronóstico de trayectorias dado por el ECENS y por el modelo determinista ECHRES, partiendo de la pasada del día 4 de septiembre a las 00 UTC. En la Figura 46.5 en la página siguiente podemos ver, en color negro, la trayectoria prevista por el ECHRES, que proponía un recurve hacia el norte de la trayectoria, como así hacen una parte de los miembros del ECENS. Sin embargo, algunos de los miembros del ECENS recurvaban el sistema hacia el sur, lo cual llevaría al impacto de Ike en la costa oriental de Cuba el día 8 , como sucedió.

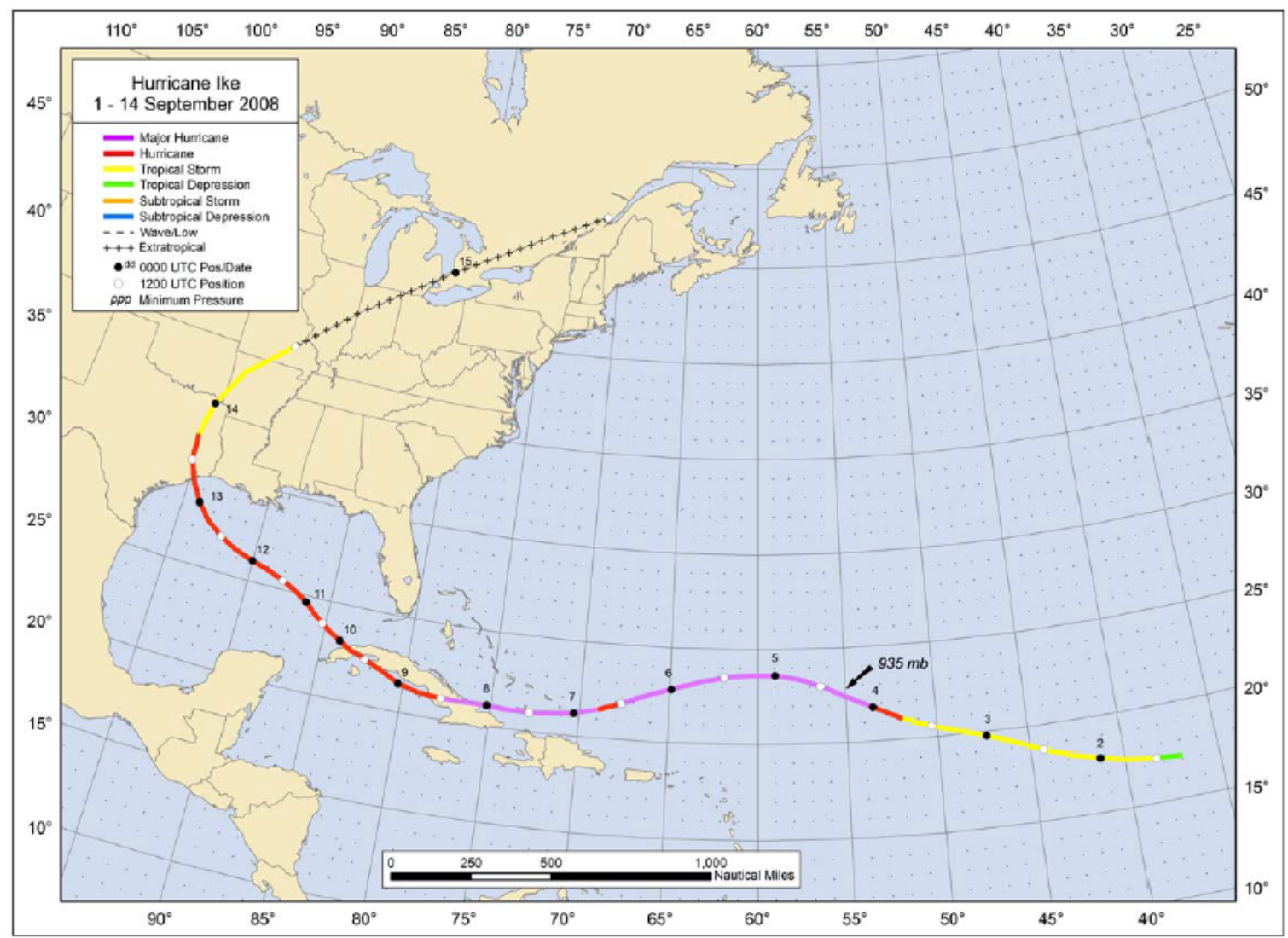

Figura 46.4: Trayectoria e intensidades del huracán IKE, 1-14 de septiembre 2008. Fuente NHC. 


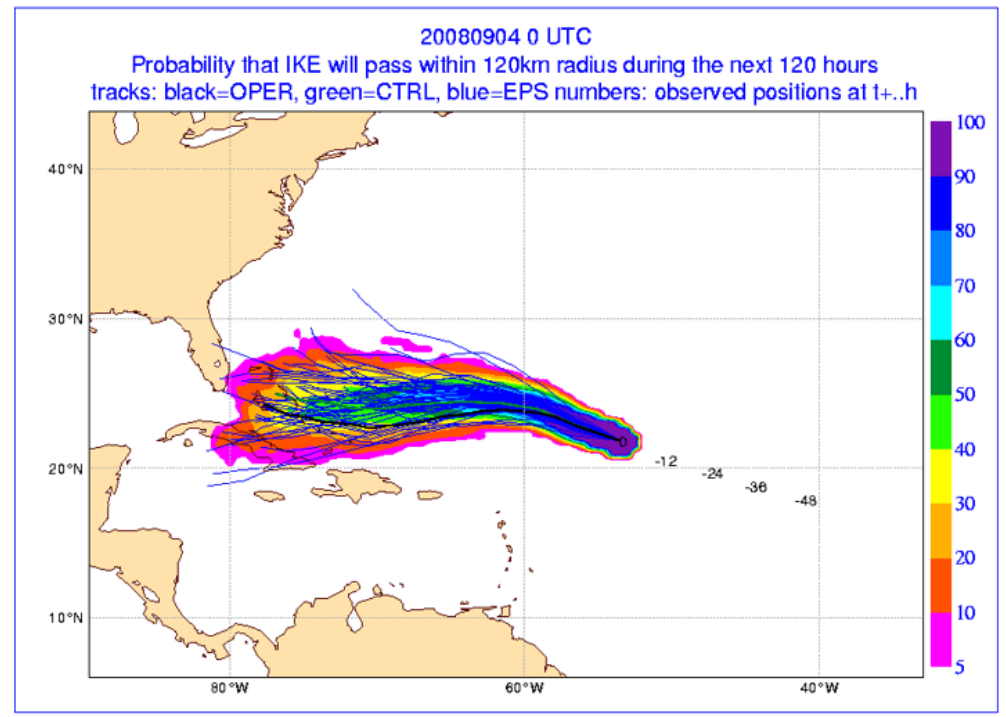

Figura 46.5: Trayectorias y probabilidades de impacto del huracán IKE para 5 días a partir del día 4 de septiembre a las 00 UTC. ECMWF 2008.

Aunque las probabilidades de impacto sobre las costas de Cuba eran bajas, no era descartable dicho impacto, y eso nos permite pensar, en base a la trayectoria observada, que el ECENS estaba funcionando bien. En pasadas posteriores, las del día 5 a las 00 y 12 UTC, la versión determinista del modelo corrige su error de recurve hacia el norte, dando lugar a un pronóstico más acertado, que vemos en la Figura 46.6A. A partir de este día Ike deja de ser un huracán candidato a resbalar por la costa oriental de Estados Unidos, como proponía la pasada de 48 horas antes, Figura 46.6B, y pasa a ser un huracán que atravesará la isla de Cuba de este a oeste, con apreciable probabilidad de impactar en la costa sur de Estados Unidos.

Las causas de este «bandazo» del modelo determinista son difíciles de determinar. Habitualmente es crucial la posición e intensidad de la dorsal subtropical de niveles medios a la hora de definir la trayectoria de los ciclones atlánticos. A menudo, los procesos de ciclogénesis de latitudes medias tienen una apreciable influencia en este sentido, pues pueden debilitar dicha dorsal y facilitar el recurve de los ciclones tropicales hacia el norte, dando lugar a las clásicas trayectorias que «resbalan» por la costa este de los Estados Unidos.
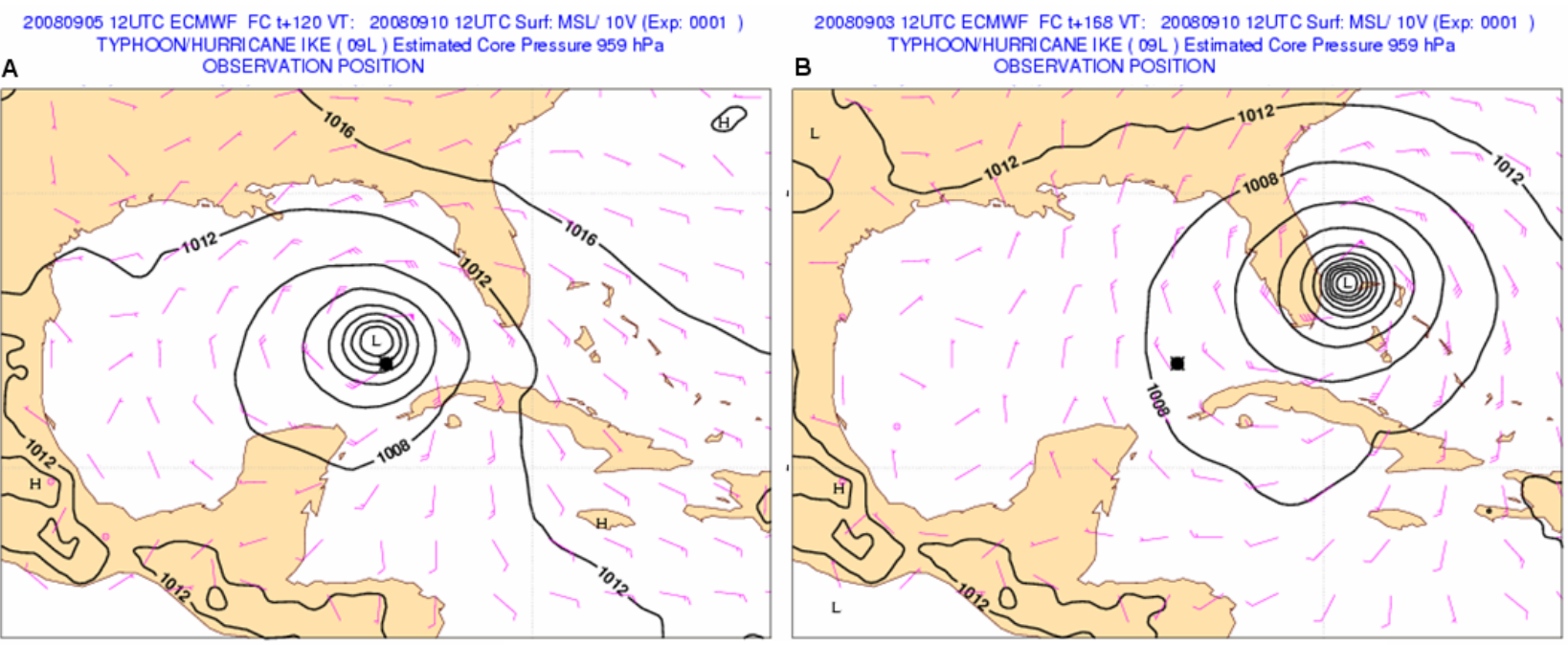

Figura 46.6: Verificación de la posición del centro del ciclón para las pasadas de las 12 UTC de los días 5 (A) y 3 (B) de septiembre. ECMWF 2008. 


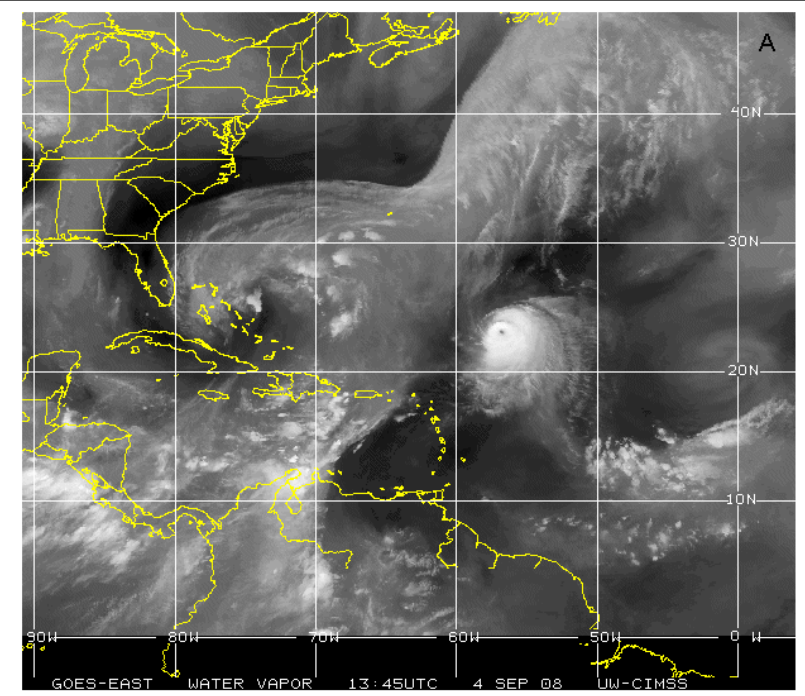

Figura 46.7: Imágenes del canal vapor de agua del 4 de septiembre a las 13.45 UTC (A) y del 6 de septiembre a las 10.45 UTC (B). Fuente: CIMSS.

En el caso de Ike, podemos atrevernos a especular un poco, gracias a la secuencia de imágenes del canal vapor de agua. A la vista de dicha secuencia, de la cual se adjuntan solo dos imágenes en el capítulo, es admisible sospechar que el modelo determinista del día 4 a las $00 Z$ no recogiera bien la interacción del ciclón tropical con un sistema extratropical próximo.

En la imagen de la Figura 46.7A, día 4 de septiembre, vemos la señal clásica de un proceso de inicio de ciclogénesis extratropical, al nor-noroeste de Ike. Si seguimos la secuencia de imágenes entre los días 4 y 6 , se aprecia de forma bastante clara la interacción y el intercambio de energía entre este sistema y el ciclón tropical. De hecho, la ciclogénesis extratropical no progresa hacia el este y termina por frustrarse,

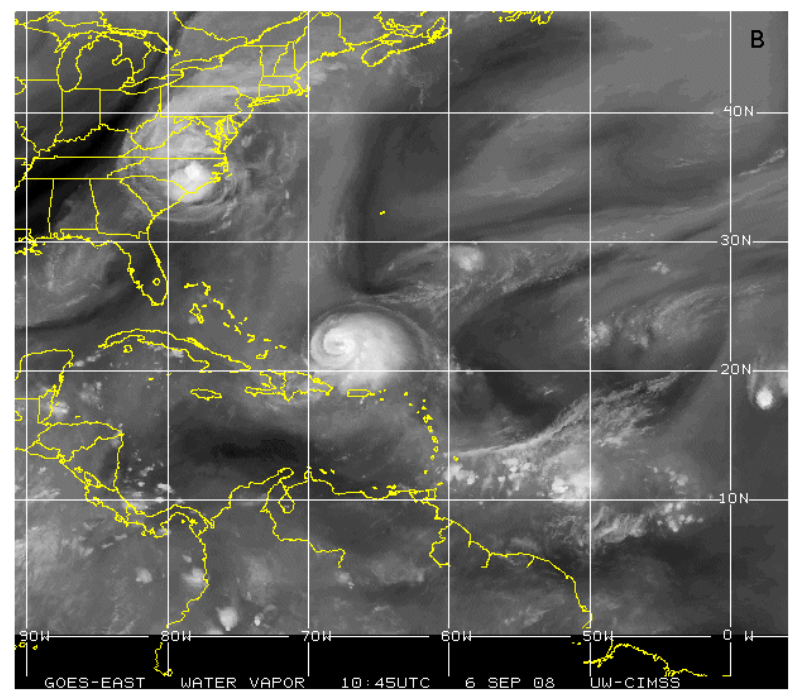

cosa bastante rara de ver, tal vez por ceder bastante de su energía a Ike. Es bastante probable que el modelo tuviera cierta dificultad para reproducir con precisión dicha interacción e intercambios de energía y esta podría ser una causa del «bandazo» entre las pasadas de los días 4 y 5 . No obstante, un estudio más detallado sería de gran utilidad y necesario para verificar esta hipótesis.

Terminada la fase de interacción y partiendo de reanálisis que ya recogen los efectos de la misma, -esto es a partir del día 5-, las predicciones de la evolución de Ike, tanto por el modelo ECHRES, como por el ECENS mejoran apreciablemente y reproducen bien la evolución del huracán, como puede verse en la Figura 46.8A.
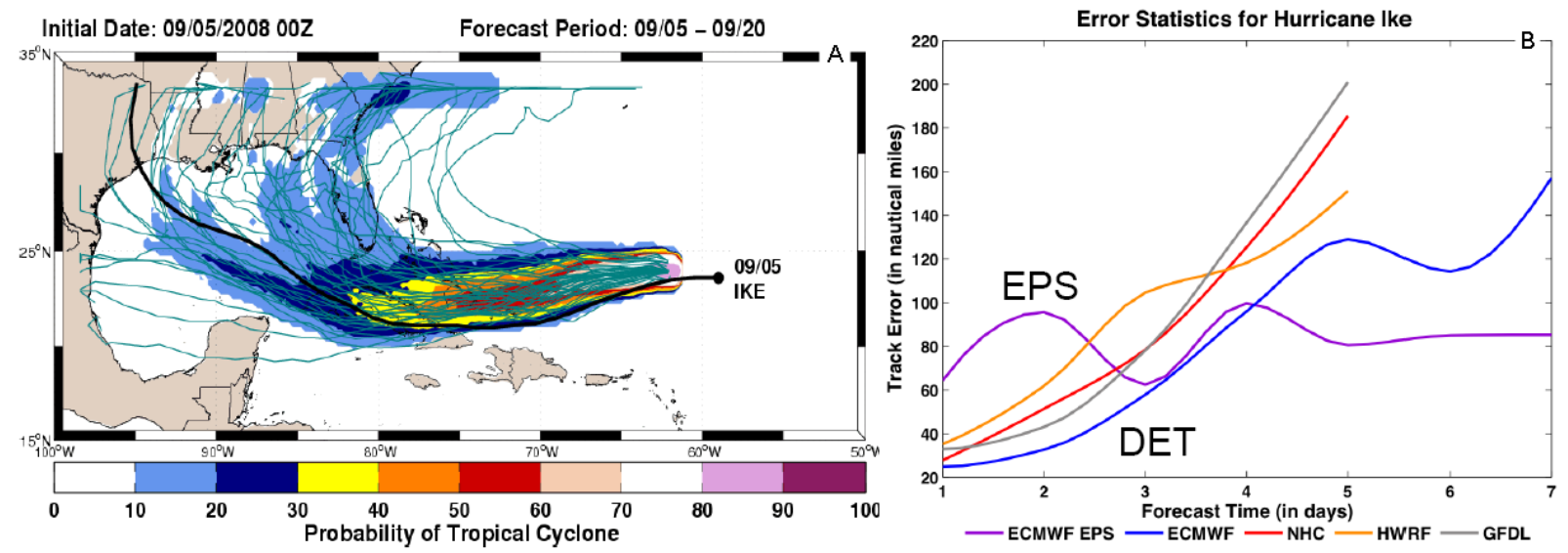

Figura 46.8: A: Probabilidades de impacto de Ike dadas por el ECENS. B: Errores de posición en la trayectoria hasta el D+7 para distintos modelos. Pasada de las 00 UTC del día 5 de septiembre de 2008 [2]. 

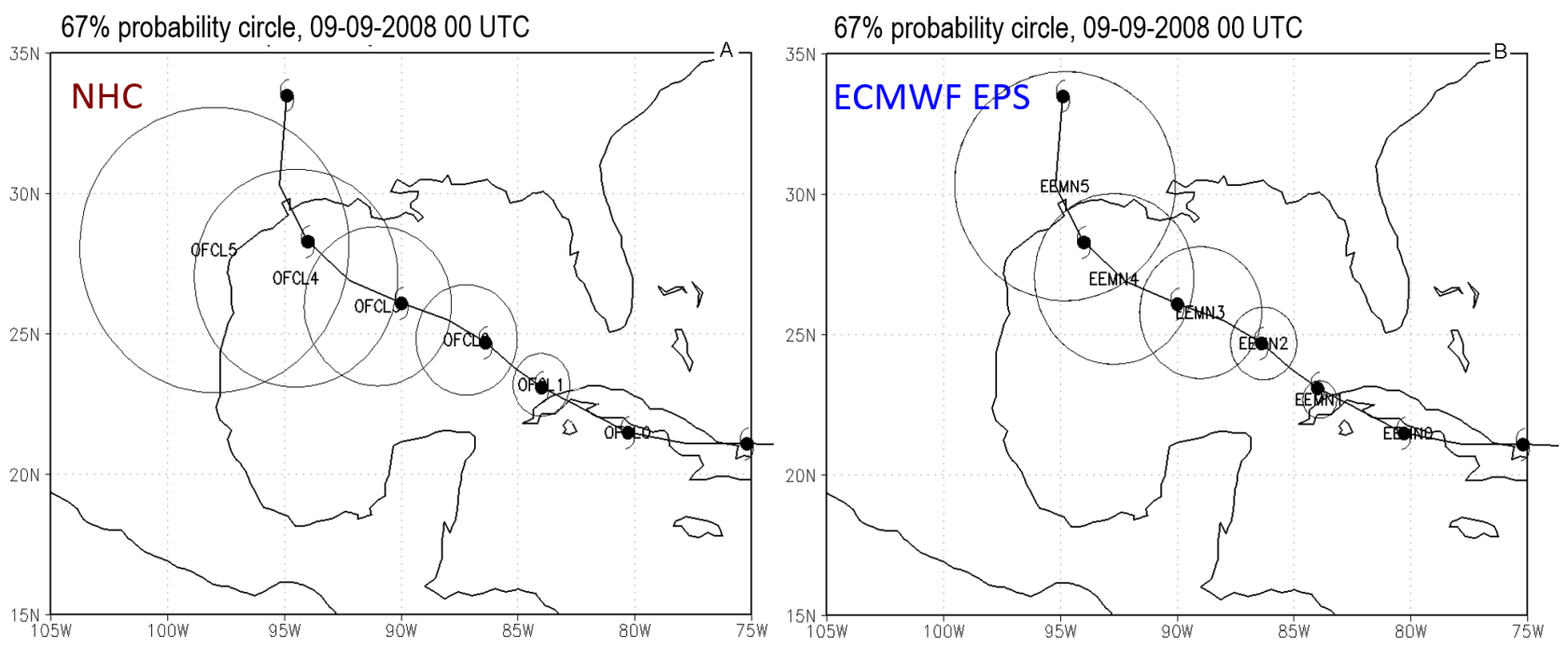

Figura 46.9: Trayectoria observada y círculos de probabilidad 67\% previstos para Ike según el modelo oficial del NHC (A) y el ECENS (B). Pasadas de 00 UTC, 09-09-2008 [7].

En la Figura 46.8 en la página anterior, parte B se muestran los errores en la predicción de la trayectoria para distintos modelos partiendo de la pasada del día 5 a las 00 UTC. Es interesante ver como a partir del día D+4 el ECENS (media de sus miembros) presenta los menores errores de posición de la trayectoria de Ike.

Volviendo a la evolución de Ike, las observaciones muestran que al final del día 9 de septiembre, después de haber recorrido la isla de este a oeste, el ciclón tropical deja Cuba. A partir de aquí el ECENS tiene un comportamiento más que aceptable para las trayectorias previstas, como muestra la Figura 46.9B, que compara las trayectorias medias dadas por el ECENS y por el modelo oficial del NHC con la observada. En este caso, la media del ECENS verificó claramente mejor que el propio ECHRES, que daba el impacto bastante al oeste de donde sucedió. Se muestran también los círculos de probabilidad que contienen el $67 \%$ de los miembros en el caso del ECENS. En el caso del NHC el círculo de probabilidad tiene carácter estadístico, como ya comentamos al principio del capítulo, y está definido a partir del percentil 67 de la distribución de los errores de posición para una muestra de casos elegidos durante los 5 años anteriores. El centro de los círculos corresponde a las posiciones dadas por el modelo oficial del NHC.
Este es el método tradicional del NHC para dibujar sus conos de probabilidad de impacto de los ciclones tropicales, explicado con más detalle en http: //www.nhc.noaa.gov/aboutcone.shtml. Es importante destacar que los conos de probabilidad, así definidos, no contienen información sobre las incertidumbres asociadas a la situación sinóptica en la que se genera y con la que evoluciona el ciclón tropical dado. Esta es una posible desventaja que no presenta un trazador basado en un SPC que siempre recoge la dinámica de la situación concreta, incluyendo perturbaciones.

\subsection{Caso 2: Huracán Álex}

El ciclón tropical Álex inicia su ciclo de vida como una depresión tropical en el mar Caribe el día 25 de julio de 2010, pasando enseguida a la categoría de tormenta tropical, carácter que mantiene buena parte de su ciclo de vida, mostrado en la Figura 46.10 en la página siguiente, tomada del Tropical Cyclone Report elaborado por el NHC para Álex. En su recorrido atraviesa la península de Yucatán y después el golfo de México, donde se intensifica apreciablemente, pasando a la categoría de huracán y llegando a tocar tierra el día 1 de julio ya casi en el extremo norte de la costa mejicana [9]. 


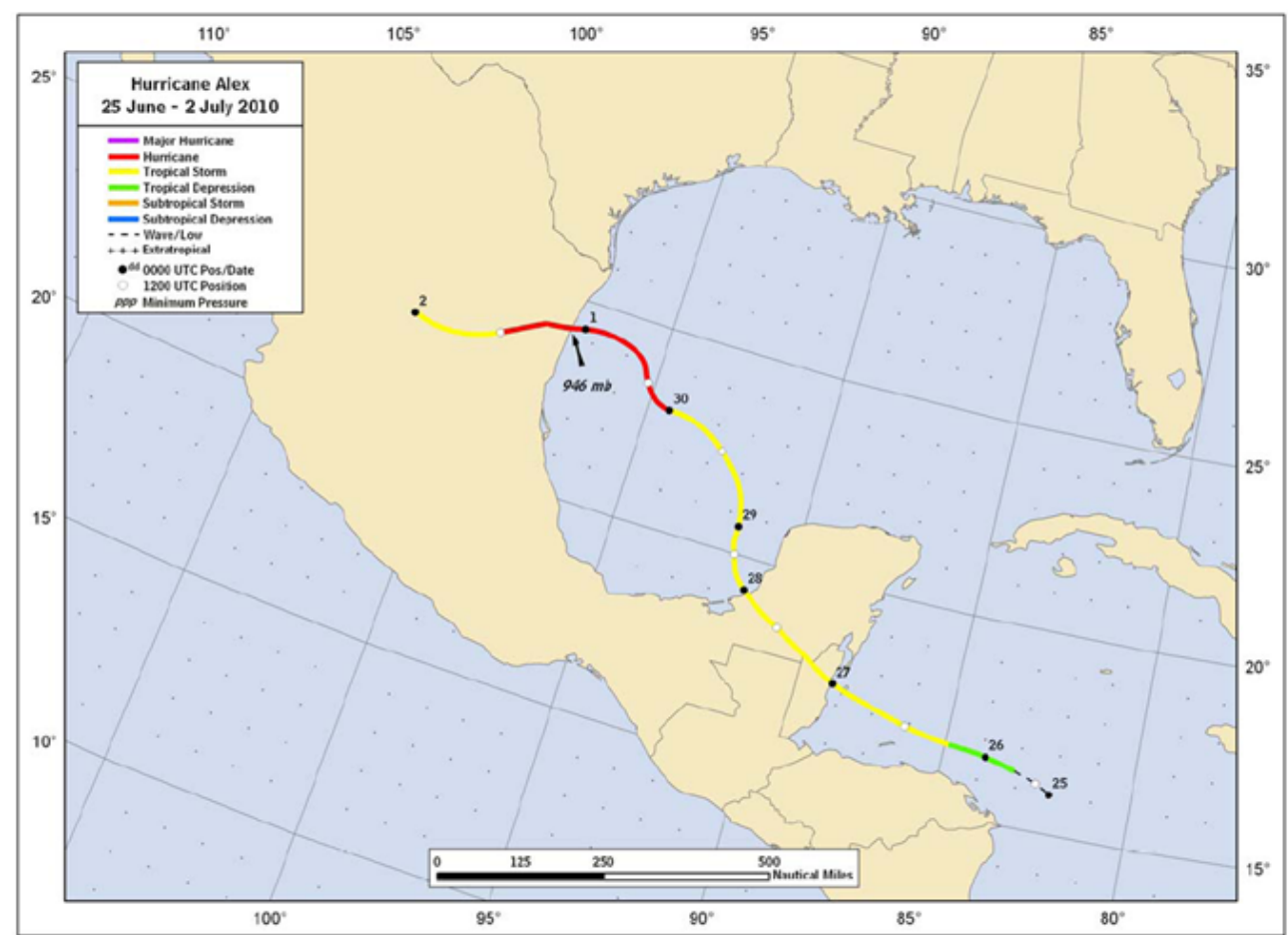

Figura 46.10: Trayectoria e intensidades del ciclón tropical ÁLEX. 25/06-02/07, 2010. Fuente: NHC.

Es curioso cómo la pasada del ECHRES del día 22 de junio a las 00 UTC, Figura 46.11, es bastante precisa en cuanto al lugar de impacto del ciclón, no así en cuanto a su intensidad ni momento de impacto, pues lo anticipa unas 24 horas. Aunque no se muestra, es importante notar que esta pasada no reproduce de forma correcta ni la trayectoria ni el ciclo de vida. Por contra, la pasada de 24 horas después, el día 23 a las 00 UTC, da un error de localización del ciclón mucho mayor y sobrestima apreciablemente la intensidad.
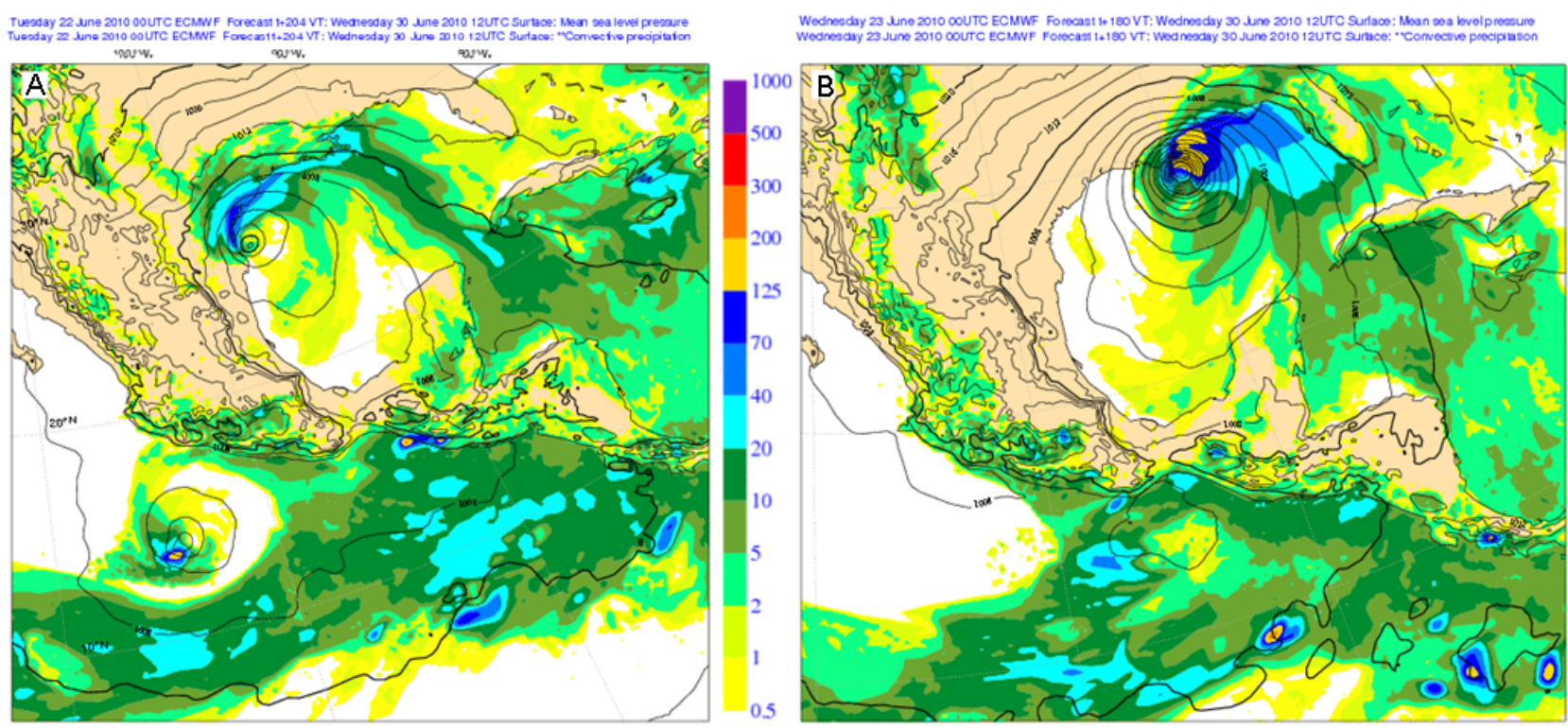

Figura 46.11: Predicción del modelo determinista del ECMWF para el día 30 de junio de 2010 a las 12 UTC. Pasadas de los días 22 y 23 de junio a las 00 UTC. Fuente: GARCía MÉndEZ, A., ponencia en el Taller sobre aplicaciones de los productos del ECMWF a la meteorología tropical, 2011, La Antigua, Guatemala. 

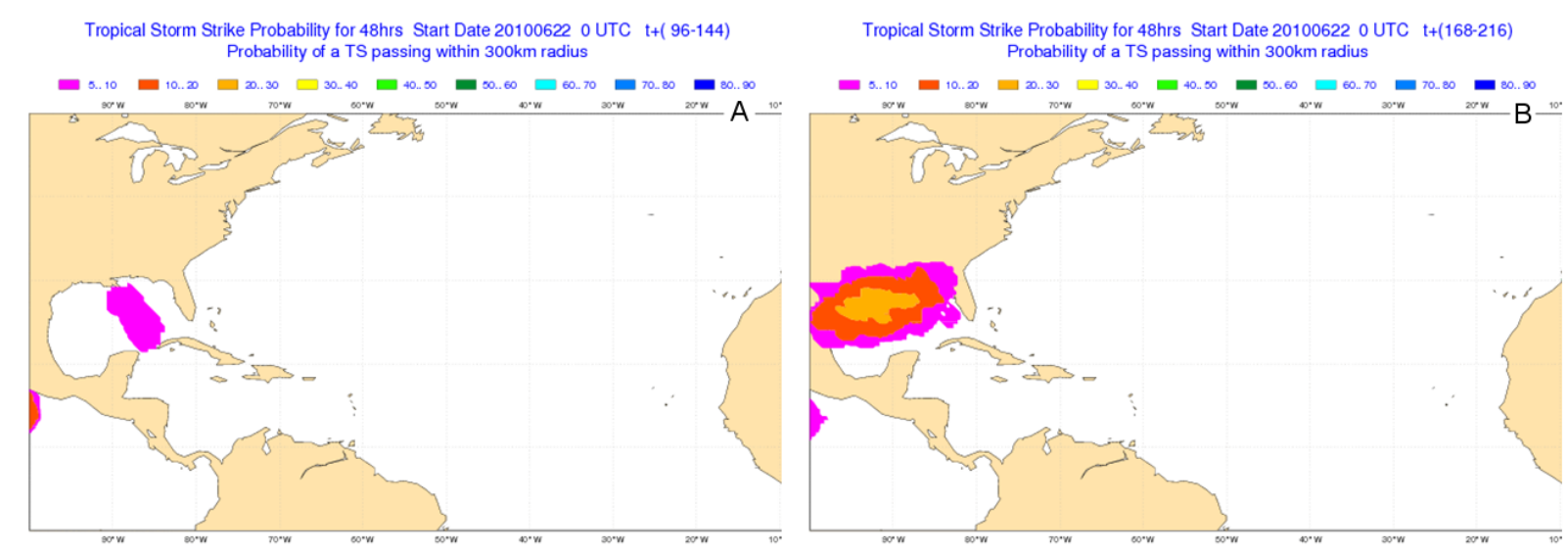

Figura 46.12: Probabilidad de que un ciclón tropical impacte en un entorno de $300 \mathrm{~km}$ de radio para los días $D+4$ a D+6 (A) y D+7 a D+9 (B), pasada de las 00 UTC del 22-06-2010. ECMWF 2010.

Si nos fijamos en las probabilidades de impacto del ECENS del día 22 a las 00 UTC, Figura 46.12B, vemos que la nube de probabilidad en el entorno del día 30 de junio (D+9) contempla las dos salidas deterministas de la Figura 46.11 en la página anterior. La probabilidad de impacto sobre la costa nororiental de México (zona del impactó en tierra de Álex) está en torno al $15 \%$, como muestra la misma Figura.

La información de los productos de un SPC pueden usarla los predictores para valorar la incertidumbre y dar distintos matices a sus pronósticos. Es llamativo y pide interpretación el hecho de que las probabilidades de impacto en el periodo D+4 a D+6, Figura 46.12A, sean tan bajas y poco extendidas espacialmente. $\mathrm{La}$ causa es, probablemente, que el modelo no llegó a generar un sistema de la intensidad suficiente como para catalogarlo de ciclón tropical en la mayoría del golfo de México. Las probabilidades de impacto que da el ECENS para la Península de Yucatán son cero o próximas a cero, a pesar de que el ciclón atravesó la misma entre el D+5 y D+6 (días 27 y 28) con categoría de tormenta tropical. De nuevo, esto puede estar relacionado, además de con errores en la trayectoria, con la intensidad que reproducen los miembros del ECENS para este sistema.

Si nos fijamos en la pasada del día siguiente, 23 de junio a las 00 UTC, tanto el ECHRES como el ECENS, generan el ciclón tropical, aunque ni el determinista, ni el miembro de control, ni la media del ECENS reproducen demasiado bien su recorrido y ciclo de vida, como vemos en la Figura 46.13A. Además, es apreciable el "bandazo" del modelo determinista en cuanto a la posición prevista para Álex.

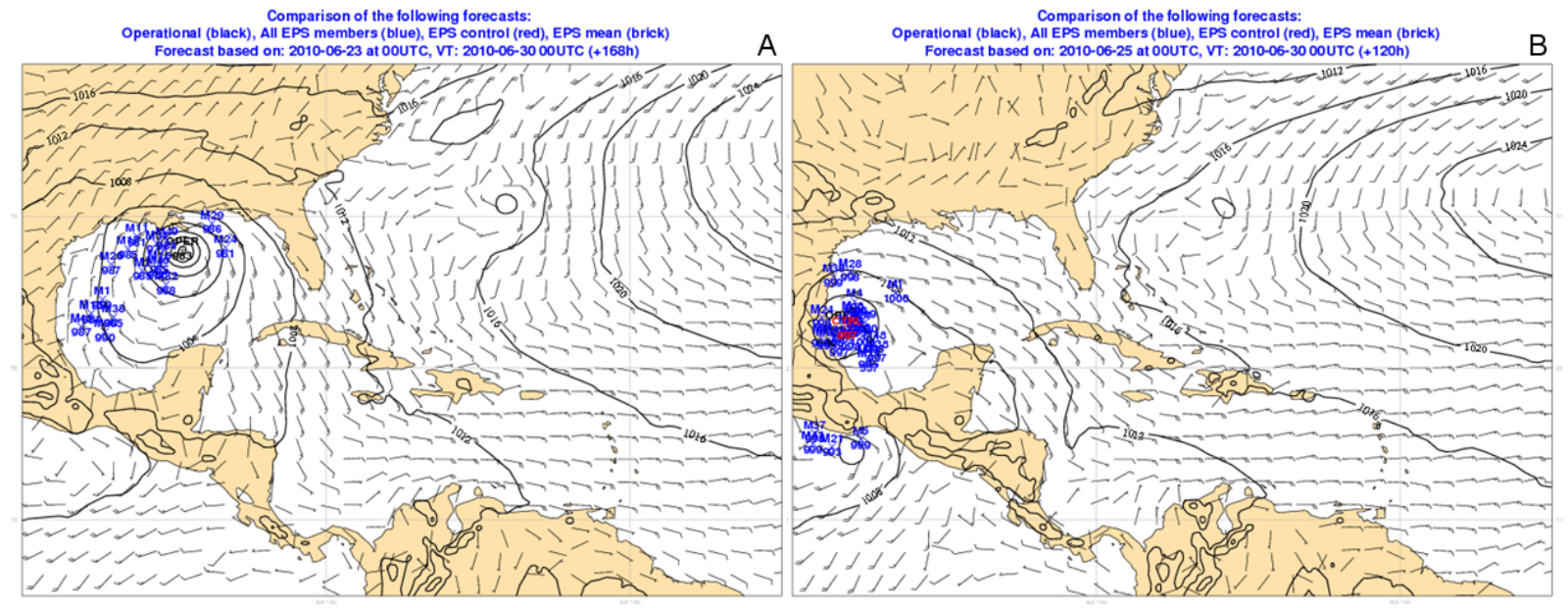

Figura 46.13: Predicción del ECHRES y del ECENS para el día 30 de junio de 2010 a las 00 UTC. Pasadas de los día 23 y 25 de junio a las 00 UTC. Fuente: GARCÍA MÉnDEZ, A., ponencia en el Taller sobre aplicaciones de los productos del ECMWF a la meteorología tropical, 2011, La Antigua, Guatemala. 
Esta nueva disposición está, sin embargo, bastante apoyada por las probabilidades del ECENS en sus pasadas de los días 22 y 23 a las 00 UTC, aunque es errónea en buena medida, según lo observado.

Estos «bandazos» en los modelos deterministas son muy típicos en el medio plazo en la predicción de ciclones tropicales y deben ser tenidos en cuenta por el predictor para «templar» la señal determinista con los productos del ECENS. En el caso de Álex los «warnings» del NHC, basados en distintos modelos, fueron un tanto confusos y cambiantes de un día para otro, lo cual habla de la incertidumbre en la génesis y en la evolución de este ciclón tropical.

Volviendo a la Figura 46.13 en la página anterior parte A, vemos que la probabilidad de impacto en la zona donde el modelo determinista genera el ciclón no es demasiado alta, pues la mayoría de los miembros del ECENS se dispersan bastante alrededor de la posición que señala el modelo determinista, quedando el máximo de probabilidad hacia el oeste de dicha posición. Tan solo unos pocos miembros del ECENS sitúan el ciclón en tiempo y lugar, es decir, en la costa nororiental mejicana, lo cual no eleva la confianza ni la focalización del predictor en esta zona, aunque al menos le permite no descartarla, cosa que probablemente haría de no contar con datos del ECENS.

La primera pasada en que el modelo del ECMWF reproduce bien el ciclo de vida de Álex, tanto en cuanto a trayectoria como a intensidades, es la del día 25 a las 00 UTC, que coincide con el día de nacimiento de Álex como depresión tropical.
201006260 UTC

Probability that ONE will pass within $120 \mathrm{~km}$ radius during the next 120 hours tracks: black=OPER, green=CTRL, blue=EPS numbers: observed positions at $t+. . \mathrm{h}$

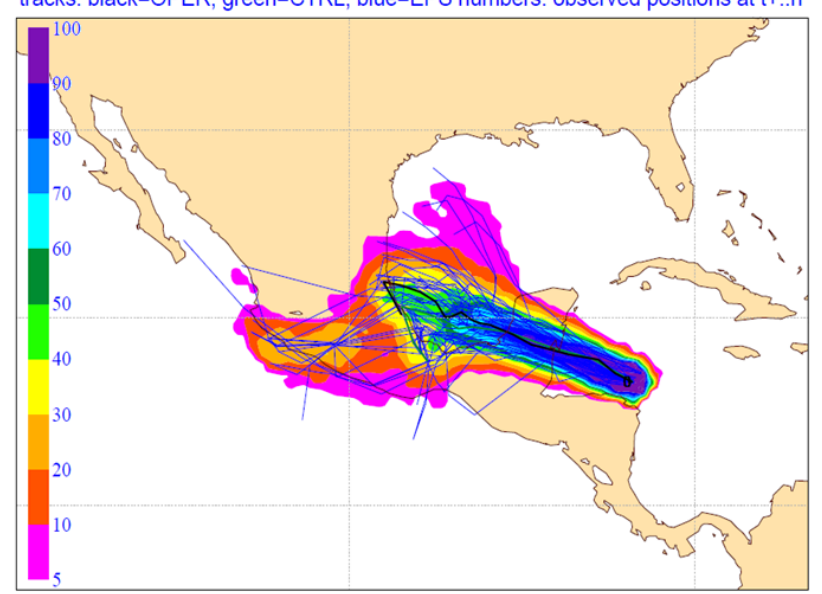

201006280 UTC

Probability that ALEX will pass within $120 \mathrm{~km}$ radius during the next 120 hours tracks: black=OPER, green=CTRL, blue=EPS numbers: observed positions at $t+. . h$

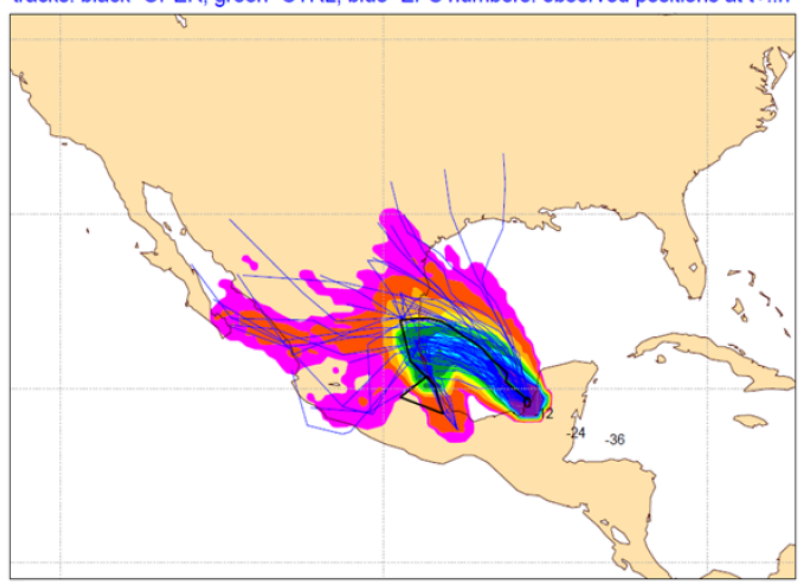

201006270 UTC

Probability that ALEX will pass within $120 \mathrm{~km}$ radius during the next 120 hours tracks: black=OPER, green=CTRL, blue=EPS numbers: observed positions at $t+. . h$

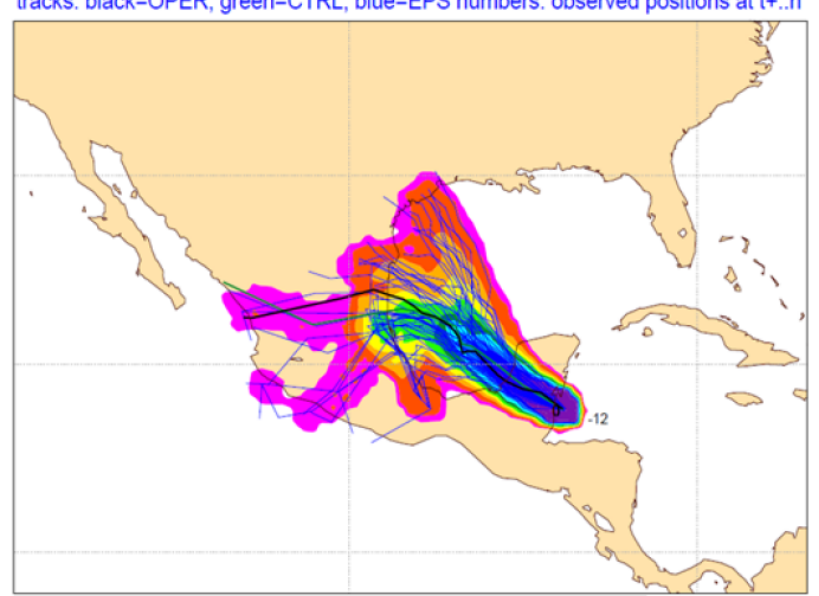

201006290 UTC

Probability that ALEX will pass within $120 \mathrm{~km}$ radius during the next 120 hours tracks: black=OPER, green=CTRL, blue=EPS numbers: observed positions at $t+. . \mathrm{h}$

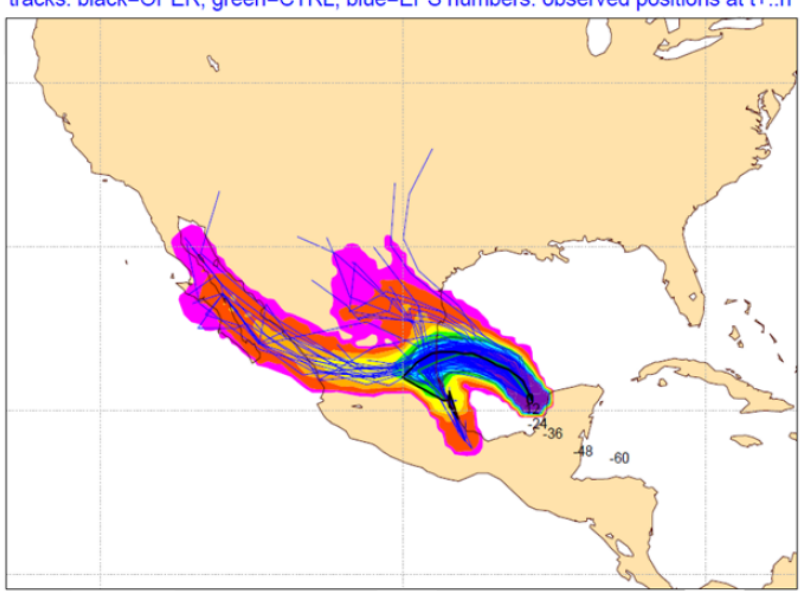

Figura 46.14: Probabilidades de impacto y trayectorias previstas $(D+0$ a $D+5)$ para el ciclón tropical Álex dadas por el ECENS y por el ECHRES a partir de las pasadas de las OO UTC de los día 26, 27, 28 y 29 de junio de 2010. ECMWF 2010. 
Una ventaja de esta pasada es que el modelo ya cuenta con observaciones precisas de la configuración del campo de presión en superficie para generar su estado inicial. Partiendo de las pasadas de las 00 UTC del día 25, Figura 46.13 en la página 725 parte $\mathrm{B}$, vemos que la probabilidad de impacto es alta (mayoría de miembros del ECENS) donde el ECHRES sitúa el ciclón, junto con el miembro de control y la media del ECENS. Esta configuración dará bastante robustez y confianza a los pronósticos que se basen en esta pasada.

A partir del día 26 las probabilidades de impacto sobre la costa nororiental mejicana dadas por el ECENS irán en aumento, como vemos en la Figura 46.14 en la página anterior. No obstante, los "bandazos" del modelo determinista se mantienen, aunque con menor amplitud que en días anteriores.

Es interesante notar que la pasada del día 25 tiene algo más de calidad o habilidad (destreza, pericia, skill, sec. 15.2.3 en la página 211) que la del día 26, la cual da probabilidades de impacto de Álex en la zona del suceso muy próximas a cero. De nuevo un ejemplo en el que se comporta mejor una pasada más lejana en cuanto a rango temporal. A partir del día 27 las cosas se van ajustando más a lo «esperable» y las probabilidades de impacto aumentan de forma considerable según nos acercamos al momento del impacto en tierra. No obstante, en ningún caso, ni el ECHRES ni los máximos de probabilidad del ECENS reproducen con precisión el lugar de impacto del huracán, de modo que la zona de máxima focalización de los avisos de un predictor que se basara en estos productos, quedaría siempre apreciablemente más al sur de donde se produjo el evento, pues en dicha zona las probabilidades de impacto están en torno al 20$40 \%$, yendo de menos a más a medida que se acorta el rango de predicción. Vemos pues, en este ejemplo, la importancia de que los pronósticos de impacto de ciclones tropicales en tierra tengan un fuerte carácter probabilista, dadas las amplias incertidumbres en las trayectorias y los frecuentes bandazos de los modelos deterministas, incluso en rangos de predicción relativamente cortos. 


\subsection{Referencias}

[1] Aemisegger, Franziska, Martius, Olivia y WÜEST, Marc. "An assessment of the ECMWF tropical cyclone ensemble forecasting system and its use for insurance loss predictions". En: 10th EMS Annual Meeting, 10th European Conference on Applications of Meteorology (ECAM) Abstracts, held Sept. 13-17, 2010 in Zürich, Switzerland. 2010 (citado en página 718 ).

[2] Belanger, James I. y col. "Predictability of North Atlantic Tropical Cyclone Activity on Intraseasonal Time Scales". En: Monthly Weather Review 138.12 (dic. de 2010), páginas 4362-4374. ISSN: 0027-0644. DOI: 10. 1175 / 2010MWR3460 . 1 (citado en página 722 ).

[3] BERG, Robbie. Tropical Cyclone Report Hurricane Ike (AL092008) 1 - 14 September 2008. Informe técnico. NHC, Miami: National Hurricane Center (NHC), 2008, página 55 (citado en página 720).

[4] ECMWF. ECMWF - Tropical cyclones. URL: https : / / www . ecmwf . int / en / forecasts/charts/tcyclone/ (visitado 03-12-2017) (citado en páginas 718-720).

[5] García Meńdez, A. y VÁzQuez PérezBATALlÓN, R. "Presentaciones". En: Taller sobre aplicaciones de los productos del ECMWF a la meteorología tropical. La Antigua, 2011 (citado en página 720).
[6] LAING, Arlene y Evans, J. L. Introducción a la meteorología tropical (requiere usuario). 2nd. COMET, MetEd, 2016. URL: http : / / www . meted . ucar . edu / tropical / textbook_2nd_edition_es/index.htm (citado en página 718).

[7] Majumdar, Sharanya J. y col. "On the Ability of Global Ensemble Prediction Systems to Predict Tropical Cyclone Track Probabilities". En: Weather and Forecasting 25.2 (abr. de 2010), páginas 659-680. ISSN: 08828156. DOI: $10.1175 / 2009 W A F 2222327.1$ (citado en página 723).

[8] National Hurricane Center (NHC). Definition of the NHC Track Forecast Cone. URL: http : / / www . nhc . noaa. gov / aboutcone. shtml (visitado 03-12-2017) (citado en página 718).

[9] Pasch, R. J. Tropical Cyclone Report Hurricane Alex (AL012010) 25 June-2 July 2010. Informe técnico. NHC, Miami: National Hurricane Center (NHC, NOAA), 2010, página 19 (citado en página 723 ).

[10] Yamaguchi, Munehiko, NaKaZawa, Tetsuo y Hoshino, Shunsuke. "On the relative benefits of a multi-centre grand ensemble for tropical cyclone track prediction in the western North Pacific". En: Quarterly Journal of the Royal Meteorological Society 138.669 (oct. de 2012), páginas 2019-2029. ISSN: 00359009. DOI: 10.1002/qj . 1937 (citado en página 718). 
